\title{
Utility of Krashen's Five Hypotheses in the Saudi Context of Foreign Language Acquisition/Learning
}

\author{
Malik Ajmal Gulzar ${ }^{1}$, Fahmeeda Gulnaz ${ }^{2} \&$ Attiya Ijaz ${ }^{3}$ \\ ${ }^{1}$ Curriculum Development and Research Unit, English Language Center, Taif University, Taif, Saudi Arabia \\ ${ }^{2}$ English Language Center, Jazan University, Jazan, Saudi Arabia \\ ${ }^{3}$ English Department, Prince Sultan University, Riyadh, Saudi Arabia \\ Correspondence: Assistant Prof. Dr Malik Ajmal Gulzar, Supervisor of Curriculum Development and Research \\ Unit, English Language Center, Taif University, Taif, Saudi Arabia. Tel: 966-582-927-088. E-mail: \\ agmsfa@gmail.com
}

Received: April 6, $2014 \quad$ Accepted: May 6, $2014 \quad$ Online Published: July 15, 2014
doi:10.5539/elt.v7n8p134 URL: http://dx.doi.org/10.5539/elt.v7n8p134

\begin{abstract}
In the last twenty years, the paradigm that has dominated the discipline of language teaching is the SLA theory and Krashen's five hypotheses which are still proving flexible to accommodate earlier reforms. This paper reviews second language acquisition (SLA) theory to establish an understanding of its role in the EFL/ESL classrooms. Other areas of SLA theory, particularly Krashen's five Hypotheses are being reviewed to provide a brief overview of SLA research in relation with Krashen's views. This paper, considering the importance of SLA theory, makes an attempt to find out how the shift in the language teaching techniques can be correlated and connected to the conceptual framework of the SLA theory.
\end{abstract}

Keywords: SLA theory, Krashen's five hypotheses, language acquisition and learning, EFL teaching methodologies

\section{Introduction}

Since the times of Socrates, educators and philosophers have advanced their arguments for a kind of teaching that does more than imparting knowledge and teaching skills. Though it has been accepted that the role of knowledge and skills is very crucial, but the true education and real teaching involves far more than this. Fundamentally, it aims at assisting learners utilize their knowledge and skills to understand, acknowledge, and struggle with significant ideas when they probe into them, and thus develop an in-depth understanding for a wide ranging and far-reaching issue and questions. Yet teaching focused on these significant targets is largely missing in Saudi classrooms. The basic reason for these missing ingredients and lagging behind is the non-implementation of SLA theories in the EFL/ESL classrooms. For the last thirty years, previous studies have been focusing on focused on solidifying knowledge about language, language teaching and learning. The integrated disciplines of Linguistics, Psychology, and Pedagogy provide teachers and learners a strong foundation on which to construct an effective theory and methodology of second language acquisition and learning. For this purpose, SLA theory has been brought to light and is believed to be the best model for teaching and learning a foreign/second language.

\subsection{Objectives of the Study}

The prime objective of the present study is "to highlight the significance of the SLA theories and Krashen's five hypotheses which are proving flexible to accommodate earlier reforms in the teaching techniques". The sole objective of the study is further divided into the following sub-objectives:

1) To understand the effectiveness of the Krashen's five hypotheses in the context of SLA theory.

2) To discuss the basic reasons which slow down the process of acquisition and/or learning due to non-implementation of SLA theory in the EFL/ESL classrooms.

\subsection{Significance/Scope of the Study}

The study may generate positive improvements in teaching and learning environment in the Saudi classrooms by having a proper implementation of the SLA theories/Krashen's five hypotheses. Above all, it may be a great help 
for teachers to know the effectiveness of these theories in reference with the EFL/ESL classrooms. Furthermore, Krashen's theory on second language acquisition (SLA) has been elaborated in simple language to communicate the meaning to the majority of teachers, and also, he used the examples from classroom state of affairs to outline the concepts. However, this theory must be adapted in varying multifaceted situations relevant to the students' acquisition and learning language scenarios accordingly. According to Krashen and other SLA specialists (Krashen \& Terrell 1983; Littlewood, 1984; Ellis, 1985), students have two different ways of developing skills in a second language: learning and acquisition. Learning is a conscious process that focuses on the structure of the language. Contrary to it, acquisition is a process which represents the subconscious activity by which new language is internalized and this process emphasizes on the meaning rather than on the structure. Acquisition is, thus, naturalistic way of acquiring the language. Naturally in the teaching of EFL context, learning is emphasized more than acquisition. Focusing on all these aspects, the present study may also assist the teachers to know how they should apply these theories to enhance the learning of the students.

\section{Literature Review}

Second Language Acquisition research originally was the inquiry of how learners acquire a second language in an English speaking environment. More recently, it has been extended to include Foreign Language Acquisition (FLA) in an environment where that language is not spoken as a native language. Van Patten (1987, p. 90). According to Ellis (1994, p. 13), "the main goal of SLA research is to characterize the learner's underlying knowledge of the L2, i.e. to describe and explain their competence". McCarthy (2001, p. 83 in Richard 2008, p. 1) defines that "throughout the 1990s, SLA theory still tended to reflect a grammar based view of language, with an interest in explaining how learners built up knowledge of the rules of the target language." Presently, limited focus of SLA theory of verbal language and the acquisition of grammatical competence largely reveals the Chomskyan influence over it. For this reason, the learning of other aspects of language such as reading, writing, or listening is deeply considered to be irrelevant (Grabe 1995). Kachru (1982, p. 209) very clearly defines that one fundamental misunderstanding pervaded in SLA literature is that acquiring a second language means being able to use it in the same manner as its monolingual native speakers. One of the most comprehensive reviews of SLA research was provided by Ellis (1994) who, according to the main research focus of SLA research has been looking for commonalities across learners just to know how individual learners perform in different age group, in different situations and with different Mother Tongue skills. Ellis further defines that there is no comprehensive theory of SLA, nor even any single theory that is widely accepted in all different situations. This reflects both the relative newness of the field and the highly complicated nature of L2 acquisition. However, Klein (1991) lists some elementary facts of both L1 and L2 language acquisition that any theory of the field must take into account. These include:

1) Language acquisition (in both L1 and L2) is a difficult process which extends over many years until full mastery is achieved.

2) Language acquisition is essentially accumulative and existence of accumulated knowledge is a condition to add further knowledge.

3) Learners can work on two types of resources at any point in their acquisition process. The first is biologically given faculties to process language and second is knowledge of the world and due to these sources language learning capacity are not considered stable.

4) The target of the acquisition process is to inter-relate expressions and meanings. It is with this aim that learners operate on the sound stream and parallel information. Learners' abstractions are driven by the idea that linguistic expressions and the rules on which they are based should make some specific sense leading towards meaningful patterns and implications. So, the language acquisition is a directed process with a clear target and understanding the process means keeping in mind this target and developing a comprehension and affiliation with the language content so to draw valid results.

5) Language acquisition is the result of many essentially interacting processes. So, Klein's summations of facts about language acquisition prove to be a valuable asset on the basis of the intricacies of the theory of SLA. Schutz also defines $(2005$, p. 1) Krashen's views about SLA and claims that "Acquisition requires meaningful interactions in the target language (natural communication) in which speakers are concerned not only with the form of their utterances but also with the messages they are conveying and understanding." Krashen explained and quoted by Schutz $(2005, \mathrm{p} 1)$ that the best methods are those that provide learners a "precise and intelligible input' in a student friendly environment, containing messages that students really want to hear. The aim of these methods is not to press students for early output in the second language, rather motivate them to give feedback when they are 'well prepared' and 'comfortable', reinforcing that change comes from providing communicative 
and easily understandable input, and not from pushing and correcting output. Krashen and Terrel (1988) define that Krashen's theory of SLA includes five main hypotheses and it is essential here to discuss briefly these hypotheses to understand their importance and role in EFL and ESL classrooms.

- The Acquisition-Learning Hypothesis,

- The Monitor Hypothesis,

- The Natural Order Hypothesis,

- The Input Hypothesis,

- The Affective Filter Hypothesis.

1) Krashen defines in the Acquisition-Learning hypothesis that second language performance carries two independent systems: "the acquired system" and "the learned system". The former is the outcome of a subconscious process very similar to the acquisition of first language; whereas the latter is the result of formal instructions and it involves a conscious process, for example knowledge and efforts towards learning the language (Krashen \& Terrel, 1988, in Schutz, 2005).

2) Schutz defines that the Monitor Hypothesis explains and establishes the relation between acquiring and learning a language. According to Krashen, the goal of "monitor" is to plan, edit and correct function in the presence of three specific conditions in second language learning, i.e. he/she has enough and appropriate time, he/she focuses on form, and he/she has sufficient understanding of the norms and principles. It reveals that in second language performance the function of conscious learning is somehow narrow and restricted. Therefore, Krashen observes that the function of the monitor is not very extended; it is used only to correct "differences or dissimilarities" from "normal" speech and to give speech a more "comprehensive" and "precise" form (Krashen \& Terrel, 1988).

3) Krashen and Terrel (1988) explains that the "Natural Order Hypothesis" is followed by the "acquisition of grammatical structures" which is foreseeable. The acquisition of grammatical structures varies from each other in different time periods: some are acquired early while others late. Krashen, however, does not suggest that a language programme syllabus should be developed in the similar order found in the studies. In fact, he was of the view that grammatical sequencing should not be applied when the aim is language acquisition.

4) Krashen (in Schutz 2005) points out that prime concern of input Hypothesis is only with the acquisition of language, not learning. It predicts that acquisition takes place in a "natural order" when the learner receives second language "input" that is one step beyond his/her present ability of linguistic competence Krashen and Terrel, (1988). Krashen (1985) noticed that older language learners learn more by having more comprehensible input that is being able to use their native language as a data resource.

5) Krashen and Terrel (1988) defines that the Affective Filter Hypothesis, manifests Krashen's point of view that in second language acquisition, a good strength of "affective variables" perform a conducive but non-causal role. These variants involve: stimulus, self-reliance and anxiety. Wong-Fillmore (1992 in Brice and Roseberry-Mckibbin, 2001) stated that learning a second language requires several conditions, which are as follow:

1) A need for communication.

2) Accessing language through native speakers of that language (parents, family members, or community members).

3) Communication, assistance, and feedback from others.

4) A close intimacy and interaction with others enduring for 3 or 4 years.

In the above mentioned five hypotheses, Krashen tried to highlight the significance of meaningful and reflective communication in the target language - natural communication - in which speakers are concerned with conveying and understanding of the messages regardless of paying heed to the form of their utterances. In fact, he noticed that in language acquisition grammatical sequencing should not be observed. Krashen enumerated three crucial aspects, i.e. motivation, self confidence and low level of anxiety, for successful learning of second language. Further Schutz $(2005$, p. 5) claims that the learners equipped with these features can learn the language more effectively. Situation opposite to it constitutes a cognitive inability that intercepts a sufficient amount of input from being used for acquisition and learning. Krashen argues that the mechanism of the acquisition of L2 is similar to the acquisition of L1 and that efforts should be made to create an environment in L2 classrooms which more closely approximate the conditions of L1 acquisition. Krashen (1981, p. 59) delineates that the fundamental 
pedagogical principal is that "any instructional technique that helps second language acquisition does so by providing comprehensible input". He hypothesizes that if L2 learners are exposed to "comprehensible input" and are provided with opportunities to focus on meaning and messages rather than grammatical forms and accuracy, they will be able to acquire morphology, and syntax, and comprehend meaning in the same way as L1 learners do. In other words, acquisition can occur naturally; as it does in the natural process, the learner develops an implicit feeling for what is correct, i.e. linguistic accuracy is also acquired naturally. Krashen's SLA theory changed rather reformulated the concept of language teaching and has suggested innovative ideas in the creative and ever changing regime of communicative language teaching. Furthermore, the implications of this theory should be employed according to the teacher's individual situation in order to obtain the best results. On the basis of proper implementation and the amalgamation of SLA theory with other teaching theories and approaches major changes can transpire in the discipline of ESL/EFL classrooms. Krashen and Terrel (1983) strongly argue strongly for a natural approach with a special focus on comprehensible input. On the other side, many researcher e.g. Long (1988) argues that Krashen's and Terrell's criteria of success in the SLA are only minimally acceptable and that their model is not an adequate one on which to base a language curriculum. Spada (1995) defines that Krashen's hypotheses do not lead to high level of linguistic accuracy or more refined knowledge. Research has shown that instruction which focuses exclusively on meanings usually results in persistent difficulties in the inter-language development of L2 learners.

Ellis (1994) explains that generally the theories which tell about the process of language acquisition are based on psychological theories of learning. For a long time, these theories have created a strong impact over each other and identified the differences between learning and second language acquisition (SLA), but Ellis selected an eclectic approach to be able to cover the most influential theories related to second language acquisition. It is pertinent to clarify here that the core premise of Second Language Acquisition (SLA) method was based on the understanding and beliefs of the development of methods and approaches about language and learning at the time Orr-Easthouse (2003). Brown (1994, p. 15) further clarifies that "You cannot teach effectively without understanding varied theoretical positions. This understanding forms a principled basis upon which teachers can choose the particular method for teaching and SLA theory has greatly affected the teaching and learning theories and has brought many changes in the classroom discourse". But in Saudi language classrooms, teaching methods are not based on a systematic view of SLA e.g. in the curricula designed for public institutions, teachers exploit the activities according to the Grammar Translation Method and most of the time use L1 in the classroom. In the private institutions' curricula has been designed to use communicative method and direct method and they hardly use L1 in the classroom. Resultantly, two classes are emerging in the society with overt differences of exposure and critical thinking. The reason for this situation is the faulty design of the curricula and no proper implementation of SLA theories in Saudi classrooms.

\section{Conclusion}

In Saudi Arabia, English language has been teaching for a long time. It may be argued that English has been taught with lesser expertise and it has also been suffering due to lack of strong pedagogical traditions. To improve this situation, it is important to encourage a move towards an eclectic teaching methods' (Kumaravadivelu 1994). It introduces a new and innovative paradigm of a teacher's role as an informed decision-maker in the classroom and specifies new directions for classroom pedagogies. Due to this reason, Krashen's hypotheses and SLA theory are even now notable pointers though there is currently a search for broader guiding principles to the complex choices teachers make in their classroom interaction. As far as the indigenous Saudi situation is concerned, the nature of such guiding principles is still far from clarity due to the focus of the curricula on the old traditional methodologies and ambiguities in the language policy. This situation gets further triggered when public sector teachers rely on the traditional methodologies due to different constraints like controlled environment where they cannot make the decisions in the classroom. Due to this reason, there is hardly any concept of teaching in the language classroom by using the techniques presented by SLA theory and Krashen's five hypotheses. Researchers influenced by post-modernist critical theories, such as Seedhouse (1996) assert that the constraints of institutional discourse are unavoidable in any account of teaching practice. As Prabhu (1990) has rightly argued that a teacher's own evolving 'sense of plausibility' is the truest guide to decision making. The situation explained in this article illustrates that the teachers should know the implications of SLA theory, Krashen's five hypotheses, and eclectic approach along with post-method conditions. If we look at the situation with reference to the teaching of English as a second/foreign language in Saudi Arabia and the objectives determined for the present article, it can be confidently claimed that true understanding of the SLA theories and Krashen's five hypotheses can bring significant changes in the country if understood and/or implemented in its true sense focusing on the indigenous situation. 


\section{References}

Brown, H. D. (1994). Teaching by Principles: An Interactive Approach to Language Pedagogy. New Jersey: Prentice Hall Regents.

Finocchiaro, M., \& Brumfit, C. (1983). The Functional-Notional Approach: From Theory to Practice. New York: Oxford University Press.

Foster, P. (1998). A classroom perspective on the negotiation of meaning. Applied Linguistics, 19(1), 1-23.

Goldenberg, C. (1991). Instructional Conversations and their Classroom Applications. Retrieved June 15, 2007, from http://repositories.cdlib.org/cgi/viewcontent.cgi?article=1114\&context=crede

Hymes, D. (1972). On communicative competence. In J. B. Pride, \& J. Holmes (Eds.), Sociolinguistics. Harmondsworth, England: Penguin Books.

Krashen, S., \& Terrell, T. D. (1983). The Natural Approach: Language Acquisition in the Classroom. Oxford: Pergamon.

Kumaravadivelu, B. (1994). The postmethod condition: (E)merging strategies for second/foreign language teaching. TESOL Quarterly, 28(1), 27-48.

Larsen-Freeman, D. (1986). Techniques and Principles in Language Teaching. Oxford: Oxford University Press.

Littlewood, W. (1981). Communicative Language Teaching: An Introduction. Cambridge: Cambridge University Press.

Nunan, D. (1991). Communicative tasks and the language curriculum. TESOL Quarterly, 25(2), 279-295.

Prabhu, N. S. (1990). There Is No Best Method-Why? TESOL Quarterly, 24(2), 161-176.

Scholefield, W. (1997). An overview of the teaching and learning of English in Japan since 1945. Babel, 32(1), 16-21, 37-38.

Seedhouse, P. (1996). ELT classroom interaction: Possibilities and impossibilities. ELT Journal, 50(1), 16-24.

Stern, H. H. (1992). Issues and Options in Language Teaching. Oxford: Oxford University Press.

Thompson, G. (1996). Some misconceptions about communicative language teaching. ELT Journal, 50(1), 9-15.

Willis, D., \& Willis, J. (2001). Task-based language learning. In R. Carter, \& D. Nunan (Eds.), The Cambridge Guide to Teaching English to Speakers of Other languages. Cambridge: Cambridge University Press.

\section{Copyrights}

Copyright for this article is retained by the author(s), with first publication rights granted to the journal.

This is an open-access article distributed under the terms and conditions of the Creative Commons Attribution license (http://creativecommons.org/licenses/by/3.0/). 